\title{
Vibration Monitoring of the Primary Piping System During the Hot Functional Tests of the Mülheim-Kärlich PWR
}

\author{
V. Bauernfeind \\ Gesellschaft für Reaktorsicherheit (GRS) mbH, Garching, FRG \\ Th. Bloem, W. Pache \\ ASEA Brown-Boveri Reaktor GmbH, Mannheim, FRG \\ H. J. Diederich \\ Rheinisch-Westfälisches Elektrizitätswerk $A G$, \\ Kernkraftwerk, FRG
}

\section{SUMMARY}

During the hot functional tests of the Mülheim-Kärlich first-of-a-kind plant, vibration measurements were made on the reactor pressure vessel and its' internals and on the primary piping system and main coolant pumps. This paper contains results of the measurements taken on the pipes and the pumps with an interpretation of these measurements based on an analytical model of the primary system.

The main aim of the measurement program is to confirm that the components, which are of new design, are adequately dimensioned for the operational vibration loads during the service life of the reactor.

In addition, the vibrational modes of the hot lines, the steam generators and the pumps with the adjacent cold lines were determined. These values were compared with the analytically calculated resonance frequencies and eigenforms. Good agreement was found. In the course of these comparisons, information on the modelling of the supporting structures and the efficiency of the damping elements during normal operation was obtained.

The vibration of the main coolant pumps was continuously monitored also. The pump surveillance system for each pump includes two non-contacting displacement sensors for measuring the kinetic shaft orbit, as well as velocity sensors for recording the vibrational velocity of the pump motor housing.

During the continuous monitoring, it was checked whether the signal amplitudes remained within the allowable limits. In addition the frequency content of the signals was determined periodically. In this way deviations could be detected immediately and be explaned by means of subsequent correlation analysis. Thus amplitude changes resulting from resonance effects were identified.

\section{INTRODUCTION}

The Mülheim-Kärlich Nuclear Power Plant is a Pressurized Water Reactor with an electric power of $1300 \mathrm{MW}$. The primary system of this first-of-a-kind plant consists of the reactor pressure vessel (RPV), two once-through steam generators (SG) and four main coolant pumps (MCP). The power station reached full load for the first time in March 1986 /Wirtz, 1987/.

The hot functional tests were performed during 1985. During these tests, vibrational measurements were made on the RPV and its internals as well as on the primary piping system and the MCP's. The object of the measurements was to prove that the operational vibrations for all system conditions lie within the allow- 
able limits; i.e. the vibrational loadings do not exceed the values specified by the design calculations. By measuring the vibration loads during the functional tests, the safe operation of the primary system for the service life of the reactor could be demonstrated.

Through analyzing the vibration measurements, the natural frequencies of the primary piping, the SG's and the MCP's were determined. For this purpose the results of the frequency analysis of the measured signals were compared with results obtained from calculations based on the analytical model.

Similarly, the vibrations of the RPV itself and the internals were investigated. Due to the close mechanical coupling between the components, in both cases the vibrational behaviour of the RPV and the loops had to be taken into account separately.

\section{MEASUREMENT AND SIGNAL ANALYSIS}

To record the vibrations of the primary piping system, 20 strain gauges were attached to one of the two loops (fig. 1). Four gauges, spaced at $90^{\circ}$ intervals on the circumferences, were attached at five different locations. These locations are designated as M1 to M5. Locations M1 and M2 are situated at both ends of the cold (discharge) line, M3 and M4 on the nozzles of the hot line and M5 at the suction line, close to the SG. In addition, two vibration velocity sensors M6A and M6B were fixed at the motor-casing of the MCP.

The analysis was performed using a data processing system (ABB-DPS), which consisted of:

- signal conditioning system (SCS)

- data recording system (DRS)

- data monitoring system (DMS)

- data analysis system (DAS)

By means of frequency-modulation a total of 168 signals in the range of $0-2 \mathrm{kHz}$ could be recorded simultaneously by the DRS. The DMS was also able to monitor up to 168 channels during test operation. Band pass filtered and temperature compensated RMS-values were compared with reference warning levels $(1.5 \mathrm{x}$ expected values) and danger levels ( $80 \%$ of the max. allowable stresses - usage factor $=1$ ).

The vibrational behaviour of the primary piping system was analysed in detail using a 2-canal FFT-Spectrum Analyzer. The Auto-Power-Spectral-Density-(APSD) function as well as the Coherence and Phase of the Cross-Power-Spectral-Density(CPSD) function were calculated for each relevant signal combination.

The APSD was used to determine the relative stress-amplitudes for the different modes of vibrations (fig. 3 ).

The amplitudes measured at the different sensor locations, were normalized for each resonance peak in the spectra. These are plotted as shown in figure 4 for M3 and M4 (frequency is $6.3 \mathrm{~Hz}$ ). The normalized values are defined as relative amplitudes and represented by the length of the arrows.

The phase of the CPSD indicates whether tension loads or compression loads occur at the different sensor positions. It is symbolized by the direction of the arrows.

In this way, all the vibration relevant modes could be plotted. Using the analytical model calculations similar characteristics were dermined and plotted. 
One loop was analyzed prior to the tests using the Finite-Segment-Program STALUM. The model for calculating the static and dynamic behaviour of the primary piping system including supporting structures and damping elements (snubbers) is shown in figure 2. The RPV was modelled by an equivalent stiffness matrix. Resonance frequencies and eigenforms were calculated considering the pipe selfweight and the weight of the fluid and the insulation. Figure 4 shows the second bending mode of the hot line.

The lowest vibration modes were calculated to be approx. 5.4/5.6/10.5 Hz (tangential/towards RPV/vertical) for the hot 1 ine and $12.9 / 11.2 / 20.7 \mathrm{~Hz}$ for the SG respectively.

\section{COMPARISON MEASUREMENT-MODEL}

Finally, these analytically calculated vibration modes were compared directly with the results of the vibration measurements. The agreement with regard to frequency, relative amplitude and phase relation was quite good for the predominant modes. Based on the measurements, the following lowest modes (see previous section) were dermined with approximate values of $4.8 / 6.3 / 11.6 \mathrm{~Hz}$ for the hot line and $14.2 / 11.2 / 22.7 \mathrm{~Hz}$ for the SG. Considerable deviations were only detected in those cases where snubber elements gravely influenced certain modes of vibration. Due to the very small vibrational amplitudes during normal operating conditions the influence of these damping elements was considered as being negligible and was thus ignored for the initial model design. The experimental results, however, showed that even vibrations in the $\mu \mathrm{m}$-region are noticably influenced by the snubbers. After modelling the snubbers as damping elements the discrepancies between model and measurements almost disappeared. The model is now so well developed that it can be used to investigate vibrational loadings of similar systems.

As mentioned before, resonance frequencies of the RPV and acoustic resonances are also contained in the Strain-APSD's, measured at the hot and the cold legs. They could be identified by detailed analysis of the RPV-vibration signals and pressure fluctuation signals from the loops /Bauernfeind, Pache, 1986/ and were neglected for the modal analysis of the loop resonances.

\section{PUMP-VIBRATION MONITORING}

The main coolant pumps are active components and therefore subject to severe thermohydraulic and mechanical loads. The pump aggregates are important for the safety and availability of a plant. For this reason the vibration of the MCP's were also continuously monitored.

The pump surveillance system includes two displacement sensors for each pump, for measuring the shaft displacement relative to the bearing housing in the seal area, as well as two velocity sensors for recording the vibration velocity of the pump motor housing.

A time-dependent and a frequency-dependent analysis of the signals was performed. During the continuous monitoring, it was checked whether the signal amplitudes remained within the allowable limits. Periodically or when deviations were detected, a frequency analysis of the signals in question was performed to find out the reason for this.

For example, during the hot functional test with the core installed, an unexpected vibration of the housing of one of the four pumps occurred. Under operating conditions the amplitudes increased - starting at approximate $1 \mathrm{~mm} / \mathrm{s}$ RMS - to clearly higher values with the peak values varying with time. For this reason the pump behaviour had to be checked in detail. Frequency analysis revealed that the changing vibrational amplitudes resulted from resonance effects. 
From the model investigations and the frequency-analysis of the loop vibration, a measured $28.0 \mathrm{~Hz}$ resonance had been identified as one of the pendular eigenfrequencies of the MCP's. At the unexpectedly vibrating pump this frequency decreased during hot condition to $25 \mathrm{~Hz}$ and even less (fig. 5). The frequency $25 \mathrm{~Hz}$, however, corresponds to the 1500 revolutions per minute of the pump shaft. As expected, an increase of the vibration amplitudes resulted when the resonance frequency passed through the predominate excitation of $25 \mathrm{~Hz}$.

The reduction of the resonance frequency was caused by a horizontal pump support which was provisionally attached. It was decided to operate this pump only during times, when its pendular resonance clearly deviated from $25 \mathrm{~Hz}$. Thus pump vibration monitoring was used directly to avoid unnecessary mechanical loading of the pump itself and of the adjacent piping.

\section{CONCLUSION}

In conclusion, it can be said that vibration measurement and monitoring is very important during the functional tests of a reactor. This procedure provides a check that the allowable stresses are not exceeded when the system is subjected to operational vibrations. The analytical models used for the design of the system, were experimentally verified. They provide a tool for detecting weak points in the system and predicting unallowable loadings on the system. Finally, they supply a good basis for successful vibration monitoring of the system for the future.

\section{REFERENCE}

Wirtz, P. (1987) The Erection and Commissioning of the Mülheim-Kärlich Nuclear Power Plant. Nuclear Engineering and Design 100, pp. 297-306.

Bauernfeind, V., Pache, W. (1986) Untersuchung der Schwingungsanregung für Reaktordruckbehältereinbauten durch Korrelationsanalyse dynamischer Drucksignale aus dem Warmprobebetrieb eines Druckwasserreaktors. Annual Meeting on Nuclear Technology ' 86 , Aachen.

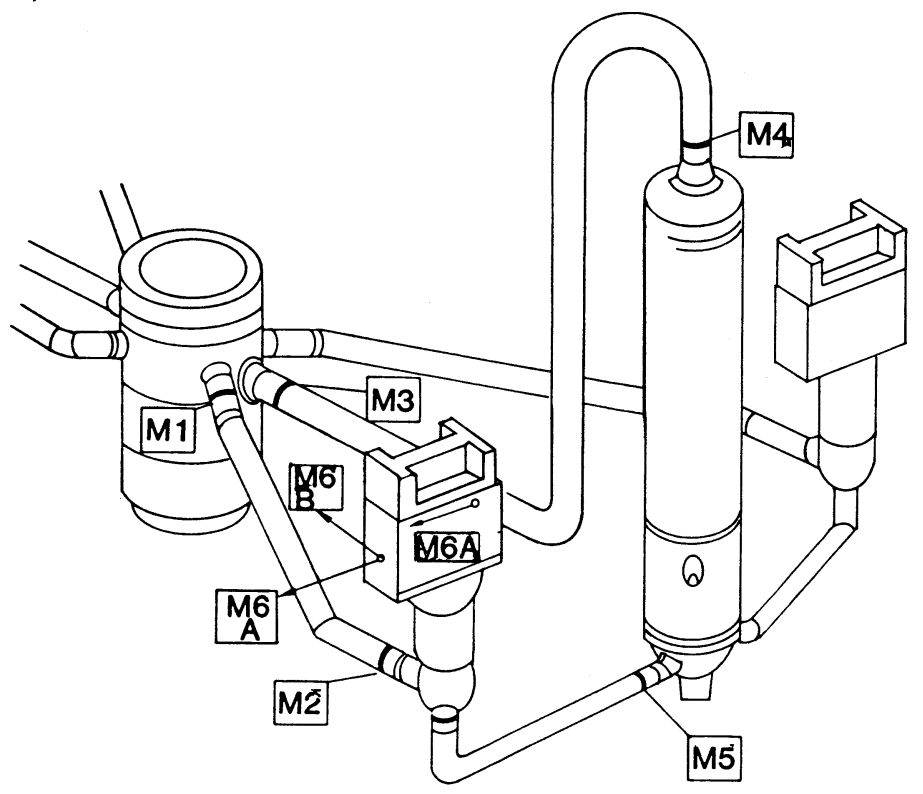

Fig.1: Primary System of the Mülheim Kärlich Reactor. Reactor Pressure Vessel and one of the two Loops, Sensor Positions 

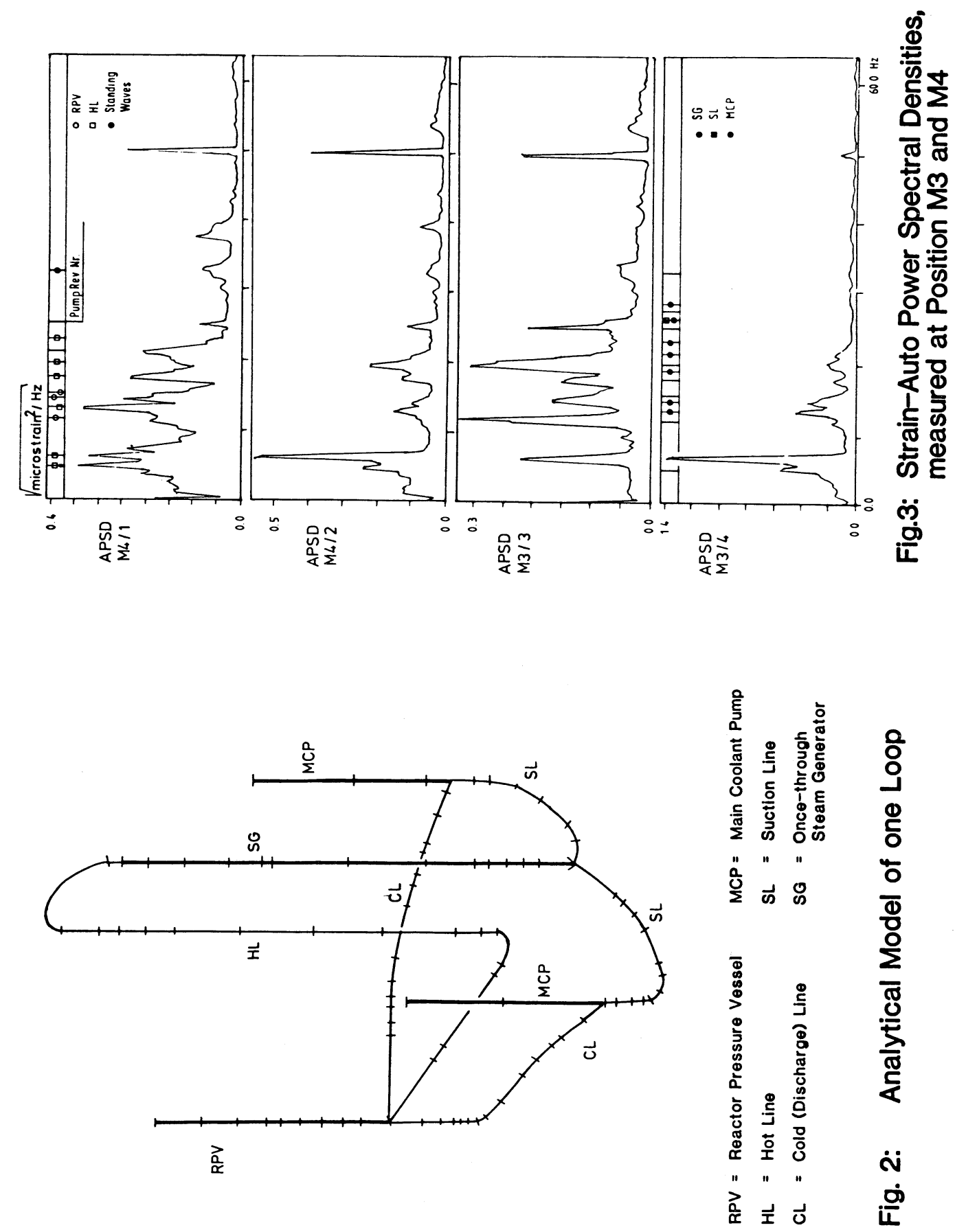


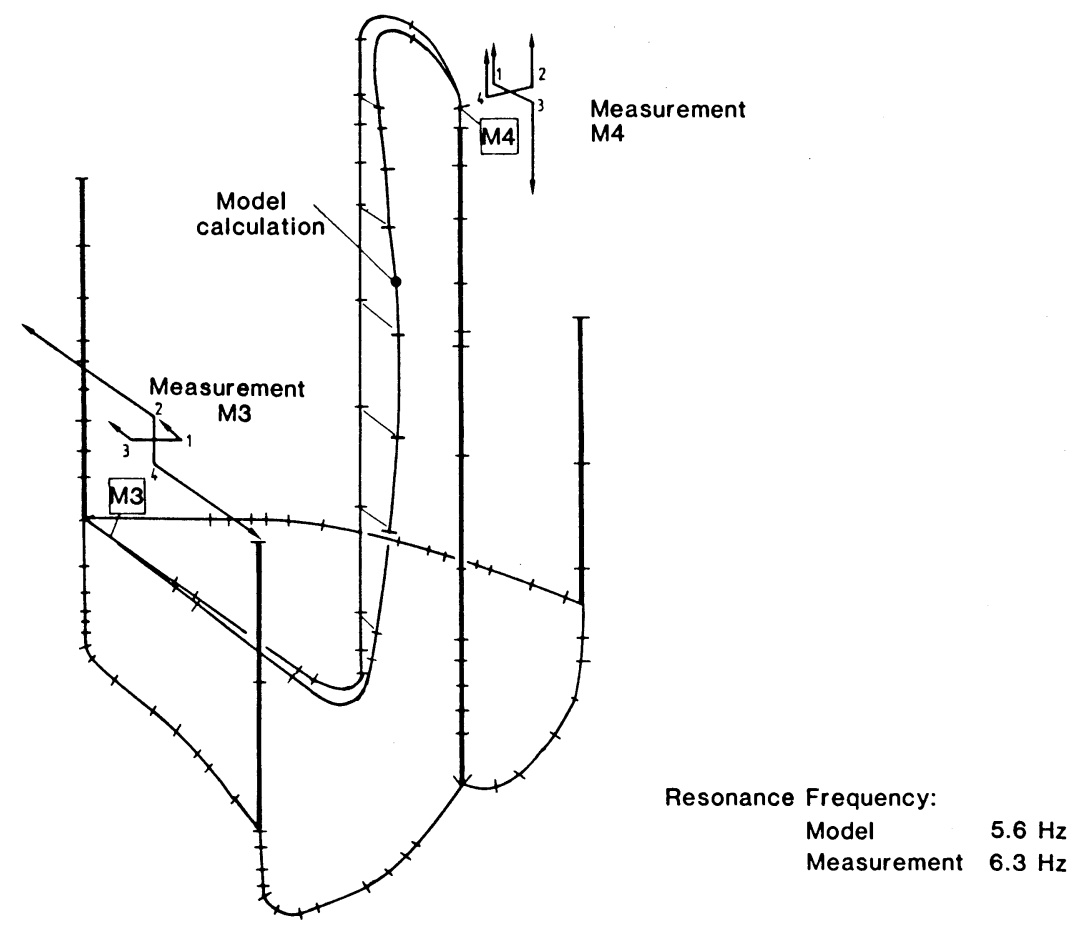

Mode: Hot-line bending Vibration

Fig.4: Hot-line bending Vibration Mode -calculated by Means of the analytical Model -measured by Strain-Gauges at M3 and M4

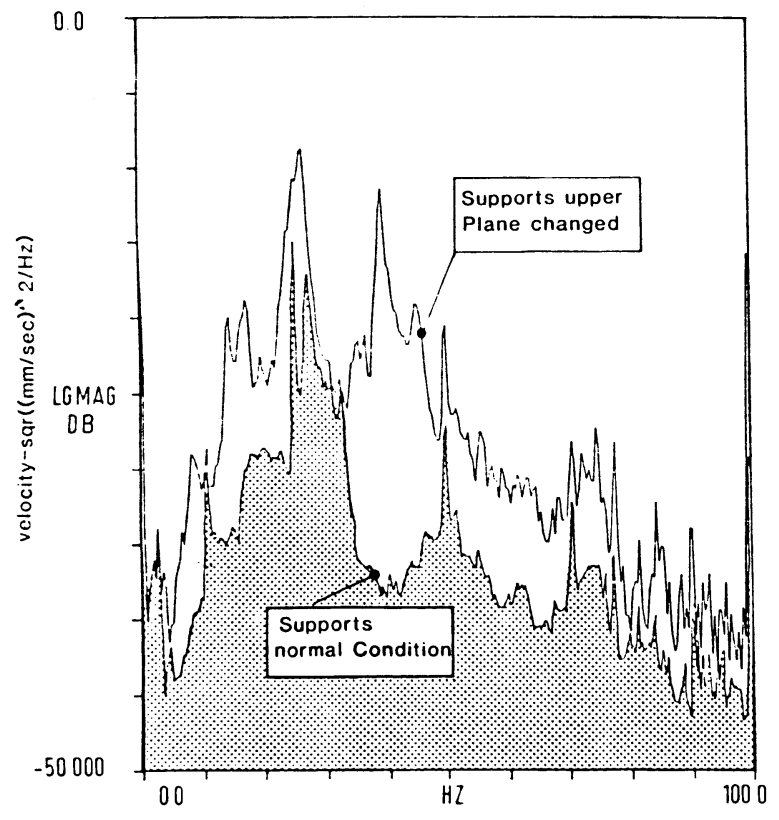

Fig.5: Auto Spectral Density of the Vibration Velocity M6A of the Main Coolant Pump

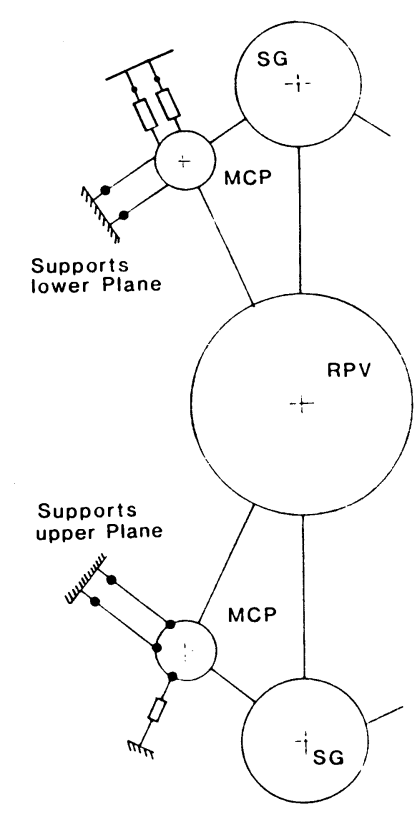

Supports of the Main Coolant Pump 